\title{
CONSTRUÇÃO DO ESPAÇO DIGITAL VIRTUAL EM TRÊS DIMENSÕES DO UNILASALLE NO METAVERSO SECOND LIFE
}

\author{
Josiane Troleiz Ferri, Centro Universitário La Salle/Unilasalle \\ Ana Margô Mantovani, Centro Universitário La Salle/Unilasalle \\ \{josi.ferri@gmail.com,margo@unilasalle.edu.br\}
}

\begin{abstract}
Resumo: Este trabalho se insere no contexto da cibercultura e tem como objetivo a construção do novo Espaço Digital Virtual em Três Dimensões (EDV3D) do Centro Universitário La Salle/Unilasalle, no metaverso Second Life (SL), a fim de garantir um espaço que represente a identidade da instituição e explore as potencialidades didático-pedagógicas dos Mundos Digitais Virtuais em Três Dimensões (MDV3D). Para tal, elaborou-se os planejamentos Urbano-Arquitetônico e Técnico-Didático-Pedagógico, além de uma avaliação qualitativa realizada através de questionários e desafios. Constatou-se que o uso de características do próprio ambiente proporcionou a construção de um espaço aberto, facilitando a locomoção dos avatares, contemplando a finalidade educacional da instituição, ampliando as possibilidades de interação.
\end{abstract}

Palavras-Chave: Metaverso Second Life, Mundos Digitais Virtuais 3D, Espaço Digital Virtual 3D, potencialidades didático-pedagógicas

\section{CONSTRUCTION OF A VIRTUAL DIGITAL SPACE IN THREE DIMENSIONS THE UNILASALE AT METAVERSE SECOND LIFE}

Abstract: This paperwork inserts itself into the context of cyberculture and has as its goal the building of a new Virtual Digital Space in Three Dimensions (EDV3D) the University Center La Salle/Unilasalle, of a Higher Educational Institution (IES), on the metaverse Second Life (SL), in order to guarantee a space that represents the identity of the institution and explore the didactic-pedagogic potentiality of the Virtual Digital Worlds in Three Dimensions (MDV3D). For such, the Urban-Architectonic and Technical-Didactic-Pedagogic planning has been elaborated, besides of a qualitative evaluation performed through questionnaires and challenges. It was found that the use of the environmental characteristics, has afforded the building of an open space facilitating the locomotion of the avatars, contemplating the educational goals of the institution, extending the possibilities of interaction.

Keywords: Metaverse Second Life, Virtual Digital Worlds 3D, Espaço Virtual Digital Space $3 \mathrm{D}$, didactic-pedagogic potentiality.

\section{Introdução}

Vivenciamos hoje a integração das tecnologias da Web 2.0 com os metaversosMundos Digitais Virtuais 3D (MDV3D), denominada de uma nova etapa da web - a Web 3D. Essas novas tecnologias estão incluídas no contexto da Cibercultura "[...], ou seja, uma nova cultura que advém da relação entre sociedade e as tecnologias, tendo como valor contido a universalidade" (LÉVY, 2008).

De acordo com Lévy (2008, p.74 - 75) um metaverso no sentido amplo "é um universo de possíveis calculáveis a partir de um modelo digital. Ao interagir com o mundo virtual, os usuários exploram e o atualizam simultaneamente." Destacam-se, como exemplos de metaversos utilizados no contexto educacional, o Active Worlds (Eduverse) e o Second Life (SL) sendo que diversas instituições de ensino utilizam ou já utilizaram o SL em experiências pedagógicas. 
Em 2008 o setor de Educação a Distância (EaD) do Centro Universitário La Salle/Unilasalle, na qual as autoras deste trabalho atuam, em conjunto com a professora coautora deste trabalho, participou de dois processos formativos no metaverso SL, onde houve o planejamento e a construção de um espaço técnico-didático-pedagógico para a instituição referida na Ilha RICESU ${ }^{1}$ no metaverso Second Life. Nesta Ilha, dividida em lotes, foi construído um MDV3D constituído por espaços comuns à Rede RICESU e por espaços destinados aos projetos específicos de cada instituição de ensino que integra esta rede, aqui denominados de Espaço Digital Virtual em 3D (EDV3D).

Em um primeiro momento, este espaço foi representado pela simulação do espaço real da parte externa de um dos prédios da instituição referida. No entanto, percebeu-se, através dos professores e alunos que utilizam o metaverso, uma dificuldade de deslocamento dos avatares no espaço construído, dentre outros fatores observados na medida em que se utilizou este espaço com objetivos didático-pedagógicos. Assim, surgiu à necessidade de dar continuidade a este projeto, buscando uma maior exploração das potencialidades pedagógicas oferecidas pelo metaverso-MDV3D, ampliando as possibilidades de uso desse espaço dentro da instituição. Partindo-se desta constatação, foi proposta a construção de um novo Espaço Digital Virtual 3D.

Assim sendo, apresenta-se neste trabalho os planejamentos Urbano-Arquitetônico e Técnico-Didático-Pedagógico que deram origem à construção do novo Espaço Digital Virtual 3D que expressa a identidade da instituição e possibilita maior exploração das potencialidades didático-pedagógicas dos MDV3D, bem como apresenta-se as suas funcionalidades.

\section{Cibercultura e as Tecnologias da $W E B$ 3D}

As novas modalidades de uso do computador na educação apontam para a discussão do uso das Tecnologias Digitais Virtuais (TDVs) como recursos didáticos pedagógicos e de possível mudança na qualidade de educação. E ainda, “[...] em função das necessidades sociais de um mundo interligado na forma de redes e da própria dinâmica da produção do conhecimento apoiada no crescimento vertiginoso das TDVs [...]" (SCHLEMMER; BACKES, 2008a, p.3), onde "[...] o conhecimento se multiplica de forma exponencial e quase tudo está disponível na internet," (MATTAR; VALENTE, 2007, p.88) surge uma nova maneira de pensar e compreender a realidade, que influencia na maneira de aprendermos, de adquirimos nossos conhecimentos.

Ainda, conforme Schlemmer, as atuais práticas didático-pedagógicas devem ser repensadas tendo em vista a utilização das TDVs no contexto educacional.

[...] Mais do que nos adaptarmos as TDVEs, é necessário que sejamos protagonizadores, autores dessa realidade, para isso é fundamental que saibamos nos movimentar nesses novos espaços puramente relacionais e nessa nova temporalidade "esticada", multissíncrona (SCHLEMMER, 2008, p.1).

Nesse contexto, destacam-se as tecnologias da Web 2.0 $0^{2}$ tais como blogs, wikis, redes sociais, sites de busca como o Google, ambientes virtuais de aprendizagem, comunidades de aprendizagem, dentre outras.

A partir da integração das tecnologias da Web 2.0 com os metaversos-MDV3D, a comunidade científica da área (como, por exemplo, Mattar e Valente (2008)), denomina de uma nova etapa da web, isto é, a Web3D. Essas tecnologias estão inseridas dentro de uma nova cultura emergente que advém da relação entre sociedade e as tecnologias, ou seja, a cibercultura.

Lemos (2003, p. 1) define cibercultura como a "forma sócio-cultural que emerge da relação entre a sociedade, a cultura e as novas tecnologias de base micro-eletrônicas que surgiram com a convergência das telecomunicações com a informática na década de 70". 
Também pode ser considerada a cultura do ciberespaço, tendo como valor contido a universalidade, onde "[...] tende à interconexão geral das informações, das máquinas e dos homens" (LÉVY, 2008, p.113), através do ciberespaço, definido pelo autor como "espaço de comunicação aberto pela intercomunicação mundial de computadores e das memórias dos computadores" (2008, p.92).

Assim sendo, no ciberespaço podemos trocar informações, bater papo, fazer partes de novas comunidades, enfim, colocar em prática a interação e comunicação, onde todos podem e devem contribuir de forma recíproca a fim de colaborar participativamente do mundo em rede em que vivemos nos dias de hoje.

Ainda, conforme Lévy (2008, p.74 - 75) o metaverso MDV3D pode se definido como "[...] Um espaço de interação por proximidade dentro do qual o explorador pode controlar diretamente um representante de si mesmo." Então, um metaverso trata-se de um espaço virtual na Internet e pode ser utilizado como sinônimo de Universo Digital (MATTAR; VALENTE, 2008) onde é possível a representação fiel ou não do espaço real do mundo físico dentro deste espaço virtual.

Segundo Schlemmer e Backes, “[...] Uma das características fundamentais dos MDV3D é o fato de se caracterizarem como sistemas dinâmicos, ou seja, o ambiente se modifica em tempo real à medida que os usuários vão interagindo com ele.” (2008b, p. 522)

Para Schlemmer e Trein um metaverso

é um termo que se constitui no ciberespaço e se "materializa" por meio da criação de MDV3D, onde há possibilidade de imersão e no qual diferentes espaços para o viver e conviver são representados em $3 \mathrm{D}$, propiciando o surgimento de "mundos paralelos". (2008a, p. 2).

Sendo assim, ainda segundo as autoras, os MDV3D possibilitam um alto nível de interatividade, uma vez que a interação acontece por meio das diferentes linguagens de comunicação: gestual, oral, textual e gráfica.

Assim percebe-se que são inúmeras as possibilidades de interação nos metaversos MDV3D, enfim, um espaço onde é possível representarmos o mundo físico ao qual fazemos parte, ou inventarmos uma criação diferente e criativa de um mundo imaginário. Toda ação e interação nos MDV3D se dá através do avatar, ou seja, a representação digital virtual de uma identidade. É possível alterar as características físicas da "identidade digital virtual", customizando aspectos de aparência. É através do avatar que se marca presença, ou melhor, a telepresença nos MDV3D, o que traz consigo novas possibilidades para a Educação a Distância $(\mathrm{EaD})$ atual.

\section{O potencial pedagógico do Second Life}

O metaverso-MDV3D considerado mais popular até este momento é Second Life (SL Segunda Vida), desenvolvido pela empresa norte-americana Linden Lab em 2003 Conforme Schlemmer e Trein (2008, p.6) o SL é “[...] um software híbrido, ou seja, possui características de diferentes ferramentas como jogos, ambientes virtuais, chats, comunidades virtuais, etc."

Schlemmer e Backes (2008) descrevem a relação que constitui o viver dentro do metaverso SL como algo que [...] torna a interação muito mais significativa, interessante, envolvente e o sentimento de pertencimento se intensifica (2008b, p.528), pois possibilita a imersão do sujeito, através da telepresença de seu avatar no ambiente em 3D, [...] e essa experiência é completamente distinta da visitação de uma página $W E B$ com informações sobre esse mesmo local e que tenha, por exemplo, possibilidades de interação por meio de um chat. (2008b, p.528)

Valente e Mattar (2008) apontam que o SL é plataforma para promover uma educação on-line e flexível, uma vez que 
[...] O Second Life oferece um conjunto de ferramentas que possibilitam fazer coisas que não é possível fazer nem no mundo real, nem no e-learning tradicional. Os professores podem compartilhar informações com seus alunos de diversas maneiras, como: textos, slides, áudios e vídeos, em ambientes que simulam a realidade. Através do ambiente virtual, os alunos podem também se conectar a colegas de outras cidades, outros Estados, outros países e outros continentes, superando, assim, a distância da educação presencial. (2008, p. 181)

Enfim, são diversas as potencialidades pedagógicas do SL, especialmente para a EaD, no entanto faz-se necessário a pesquisa e o planejamento para o uso adequado dessa tecnologia, a fim de explorar todo o potencial pedagógico oferecido.

Como concluem Schlemmer e Backes:

Voando pelas ilhas do Second Life, encontramos diversas instituições de ensino [ ...], que já oferecem algum tipo de processo formativo utilizando essa tecnologia. No entanto, quanto às metodologias utilizadas nos cursos abertos, o que observamos é uma certa transferência das metodologias tradicionalmente conhecidas para o Second Life. [...] Usar uma nova tecnologia não garante inovação, a inovação está na forma criativa de utilizá-la, na forma como aproveitamos todas as potencialidades para os processos de ensino e de aprendizagem [...] (SCHLEMMER; BACKES, 2008b, p. 530)

\section{Construção do novo Espaço Digital Virtual 3D do UNILASALLE no metaverso Second Life}

Para construção de um MDV3D e/ou EDV3D, após a aquisição de uma Ilha no metaverso, é necessária a realização de uma avaliação do espaço tendo como subsídio um projeto, um plano do que será construído.

Neste projeto devem estar incluídos o Planejamento Urbano e Arquitetônico (PUA) e o Planejamento Técnico Didático-Pedagógico do MDV3D (PTDP).

\subsection{Planejamentos Urbano e Arquitetônico (PUA) e Técnico-Didático-Pedagógico (PTDP) do EDV3D}

Conforme os estudos realizados pelo Grupo de Pesquisa em Educação Digital (GPEdu UNISINOS/CNPq), da mesma forma que, para construir uma cidade física é necessário fazer um planejamento, também se deve planejar a construção de uma cidade digital-virtual até mesmo para ter um melhor aproveitamento do espaço, poder visualizar a cidade e/ou o espaço a ser construído como um cenário a ser percorrido e reconhecido, localizando seus elementos mais importantes. Para tal, devem-se seguir algumas diretrizes no Planejamento Urbano e Arquitetônico do Espaço Digital Virtual (PUA), tais como:

"Conhecer o conceito que se deseja aplicar, de acordo com o projeto pedagógico da IES; Elaborar um desenho, layout [...]; Refletir sobre as características do espaço a ser construído: será uma representação do presencial físico e suas características ou utilizará as potencialidades dos mundos virtuais?" (BRUSCATO et al., 2008, p. 2).

Também se deve considerar questões pertinentes ao funcionamento do espaço, qual sua finalidade, o que se quer construir e de que maneira, para assim dimensionar um espaço para edificações, se ficarão suspensas ou não, e após definir a organização arquitetônica do espaço destinado à instituição dentro do metaverso SL. Conforme aponta Bruscato et al:

É importante destacar que os mundos virtuais são de natureza digital virtual, o que possibilita ir além da simulação do presencial físico, sendo possível a criação de ambientes que extrapolam as leis da física e que não seriam possíveis no presencial físico (2008, p. 2).

Em relação ao planejamento técnico é necessário considerar os requisitos relacionados ao desenvolvimento tecnológico do EDV3D, tais como configurações necessárias para execução do SL, otimização da unidade mínima utilizada para a construção dos objetos 3D (economia de prims $^{3}$ ), utilização de scripts referentes a Linden Script Languaje (L.S.L- 
linguagem utilizada no SL), compra de Lindens (moeda utilizada no SL é a Linden Dollar) etc.

O planejamento didático-pedagógico fica atrelado aos objetivos relacionados aos processos de ensino e aprendizagem, uma vez que:

[...] é preciso considerar o paradigma educacional, bem como a concepção
epistemológica que expressa à compreensão que se tem de como a aprendizagem
ocorre, a qual poderá, por meio do planejamento técnico, ser traduzida na
representação gráfica do MDV3D e nas ferramentas tecnológicas capazes de
suportar processos de interação que atendam a diferentes práticas e processos de
mediaçãa pedagógica (SCHLEMMER et al, 2008, p. 1 e 2).

Assim, conforme a autora referida, para elaborar um planejamento técnico-didáticopedagógico é necessário pensar em questões que devem ser analisadas de acordo com o projeto a ser realizado pela instituição, tais como: a existência ou não de uma cultura de TDVs na instituição onde o ambiente MDV3D está sendo proposto; o público que irá interagir com o MDV3D, os objetivos em utilizá-lo e, sob que paradigma educacional será utilizado, se o público e os professores que estarão envolvidos no desenvolvimento das atividades do processo educativo estarão aptos para utilizar essa tecnologia.

Para a construção do novo EDV3D, além de considerarmos os planejamentos referidos, também consideramos necessário fazer um estudo da constituição dos espaços educacionais existentes no metaverso Second Life. Nesse estudo observamos os EDV3D de Ilhas voltadas para educação relacionados com os seguintes aspectos: concepções de ensino e aprendizagem; chegada do avatar na Ilha; facilidade de localização dos espaços dentro da respectiva Ilha; espaços destinados para apresentações para grande número de avatares e salas de aulas virtuais. Dentre as Ilhas visitadas, percebemos que a maioria representa espaços de aprendizagem "abertos" nos quais se percebe maior possibilidade de interação e construção de conhecimento de uma forma conjunta, expressando assim uma concepção construtivista e sócio-interacionista de aprendizagem. No entanto, chamou-nos a atenção a representação de algumas salas de aulas virtuais, onde encontramos a representação de uma visão tradicional de ensino, com classes enfileiradas (conforme a maioria das salas de aula em estrutura física real), o que não contribui para interação e trabalho em equipe, assim como dificulta o deslocamento dos avatares.

Desse modo, tendo em vista a construção de um novo EDV3D para representar a identidade da instituição e possibilitar maior exploração do potencial didático-pedagógico dos MDV3D, formou-se uma equipe interdisciplinar composta por estas autoras, a coordenadora do curso de Design de Produto do Centro Universitário La Salle/Unilasalle, Prof ${ }^{a}$ Dra. Underléa Bruscato e uma a aluna Cristina Martins do curso Computação - Licenciatura, que desenvolveu as aplicações educacionais em 3D (conteúdos interativos através de animações, simulações, etc.) no espaço denominado Ateliê Digital Virtual do novo EDV3D da instituição. Para o estudo da Linguagem $L S L$ e a Modelagem 3D de Objetos, dentro do metaverso Second Life, contamos com a assessoria técnica de uma Designer Instrucional, integrante de um Grupo de Pesquisa na área de Educação Digital.

A partir do estudo da constituição dos espaços educacionais no metaverso SL e dos encontros com a equipe interdisciplinar, definimos que o novo EDV3D seria representado com características da natureza do meio, que é digital virtual. Assim, na construção do novo EDV3D, não representamos as construções físicas do meio real, pois optamos pela construção de um ambiente aberto e amplo, que expressasse uma concepção epistemológica sóciointeracionista de ensino e aprendizagem, em consonância com a filosofia da instituição a ser representada, além de facilitar a locomoção e vôo dos avatares. Nesse sentido, no novo EDV3D, o avatar pode chegar a este espaço não só pela entrada principal, mas por qualquer andar que ele desejar (de um modo diferente do atual prédio), através de uma central de teleporte disposta na entrada principal, bem como em todos os andares do mesmo. 
Para representar a identidade visual da instituição (como uso de cores, logotipos, website, etc.), aplicamos o design já existente às construções digitais virtuais. Todos os layouts foram definidos através de sketchs ${ }^{4}$ com o uso do software SketchUp da Google e as texturas utilizadas foram desenvolvidas com o software Adobe Photoshop CS4.

Consideramos importante destacar que este trabalho não contempla questões de acessibilidade para pessoas com necessidades educativas especiais. $\mathrm{O}$ termo acessibilidade aqui utilizado, refere-se à acessibilidade virtual, isto é, opções de deslocamento dos avatares que pode ocorrer através das rampas de acesso existentes em cada andar, bem como através da Central de Teleporte ou também da possibilidade de vôo de um andar para outro.

Apresenta-se nas Figuras 1 e 2 o espaço atual da instituição e o esboço da estrutura do novo EDV3D com a descrição da constituição dos andares após os planejamentos (PUA e PTDP).
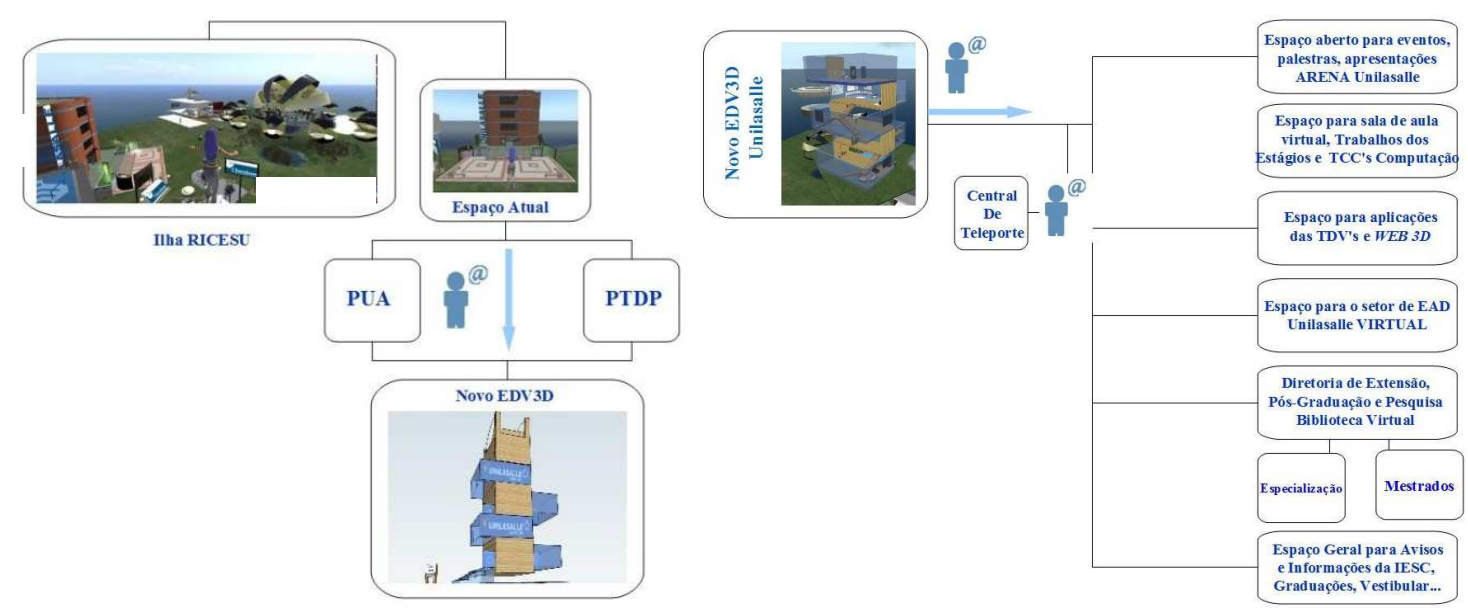

Figura 1 e 2. Diagrama principal do espaço atual versus a representação do novo EDV3D.

Fonte: Autoria própria, 2010

\subsection{DESCRIÇÃO DO NOVO EDV3D DO UNILASALLE}

Ao chegar ao novo EDV3D, encontram-se degraus amplos nas cores utilizadas na logomarca do Unilasalle, bem como a central de teleporte. Este espaço foi pensado como o espaço inicial, destinado para a recepção dos avatares.

A central de teleporte, que pode ser encontrada não somente na entrada principal do novo EDV3D, mas também em todos os andares, contém uma imagem do sketch do EDV3D com os respectivos teleportes, bem como uma breve explicação de cada andar. Foi construída em forma de um Painel Integrador, disposto próximo às rampas de acesso, que por sua vez foram protegidas por objetos invisíveis para que os avatares não caiam das mesmas, ou seja, planejadas e construídas para que, caso esbarrem nesses objetos (invisíveis), continuem sobre a rampa. Também foi desenvolvido um Objeto de Ajuda disposto em todos os andares em forma de notecards ${ }^{5}$ contendo instruções de utilização de determinados recursos dos espaços.

\subsection{Descrição dos andares}

O primeiro andar foi destinado para conhecer a Instituição de Ensino Superior (IES) Unilasalle, através de vídeos, animações, e slides show com fotos da instituição. Também se encontra o espaço vestibular para divulgação das campanhas de marketing da instituição, bem como a relação dos cursos oferecidos e link para o site de matrícula, ativo em época de vestibular, e avisos gerais. Aqui também foi construído um pequeno espaço de convivência digital virtual para os avatares. 
O segundo andar está composto pela Diretoria de Extensão e Pesquisa para apresentação e utilização dos cursos de pós-graduação Lato sensu e Stricto sensu, e com espaços para slides show contendo apresentações de trabalhos e com duas telas de mídia para acesso aos sites dos cursos de pós-graduação. Nesse espaço encontram-se mesas e cadeiras dispostas em círculo e também um mezanino (para maior aproveitamento deste espaço) que podem ser utilizadas como "salas de aula virtuais", enfim é um espaço aberto para atividades pedagógicas, aulas na modalidade à distância, reuniões, etc. Nesse andar, separado por painéis, também se encontra a Biblioteca Virtual composta por estantes com links para acesso ao site da biblioteca da IES e às diversas Bibliotecas Digitais, periódicos e demais fontes de pesquisa.

O terceiro andar foi destinado ao setor de Educação a Distância da IES, com apresentações em slides shows da estrutura do setor, da metodologia e tecnologias utilizadas para as disciplinas ministradas a distância por professores da instituição. Nesse andar também disponibilizamos uma "sala de aula virtual" disposta em círculo e um espaço de "convivência" para os avatares.

O quarto andar foi destinado às aplicações das TDVs e das tecnologias da Web $3 D$ no qual implementou-se um espaço temático denominado Ateliê Digital Virtual. Nesse espaço foram desenvolvidas aplicações educacionais contendo: Tecnoteca, Explorando o Second Life e Espaço de Interações. Através de banners, slides show, vídeo-aulas, machinimas (vídeos filmados em mundos virtuais) e painéis com projetos de aprendizagem multimídia desenvolvidas nas disciplinas ministradas pela professora co-autora desse trabalho, apresentam-se as potencialidades didático-pedagógicas de diversas TDVs e das tecnologias da Web $3 D$, bem como formas de utilizá-las e aplicações que facilitam o uso dessas tecnologias pelos iniciantes. Aqui também se encontram, até este momento, as maiores possibilidades de interação dos avatares com o próprio metaverso Second Life, através do "Espaço de Interações", que permite aos avatares interagirem com objetos através do Painel dos Desafios (disponibiliza notecards com a descrição dos desafios a serem realizados); Mural de Interações (permite a postagem e compartilhamento de notecards); Mural Multimídia (permite postar e compartilhar fotos, áudios e anotações).

$\mathrm{O}$ quinto andar foi dividido em uma sala de aula virtual e um espaço para processos formativos por professores da instituição que desejam utilizar esse espaço. No topo do prédio, encontra-se a Arena. É um espaço destinado a eventos na modalidade à distância como: apresentações de trabalhos, palestras, seminários, congressos e eventos em geral, bem como a realização de processos formativos. Possibilita uma recepção adequada para maior quantidade de avatares por ser um espaço aberto composto por vários espaços de convivência digital virtual: arquibancadas, mesas, cadeiras, tapetes e almofadas.

$\mathrm{Na}$ figura 3 apresenta-se o resultado final da construção do novo EDV3D aqui referido.

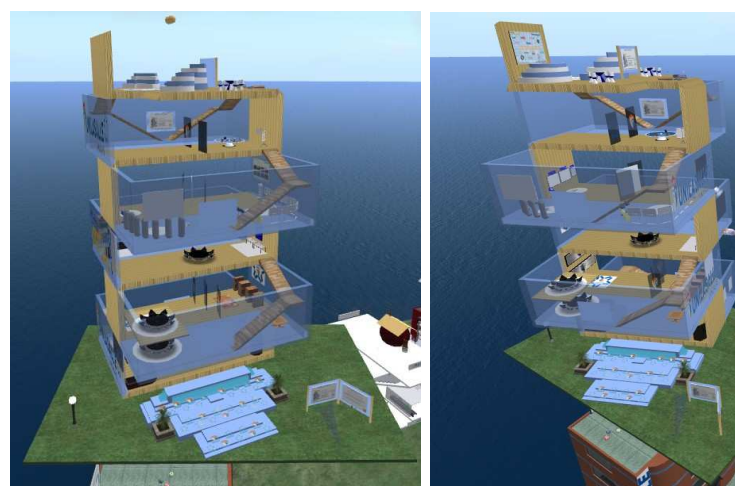

Figura 3 e 4. Fase Final do Novo EDV3D

Fonte: Autoria própria, 2010 


\subsection{AVALIAÇÃO DO NOVO EDV3D}

A avaliação do novo EDV3D foi realizada de forma qualitativa na modalidade $b$ learning (encontro presencial e a distância) sendo que o campo empírico constituiu-se de alunos provenientes dos cursos de Computação - Licenciatura, de colaboradores de um Grupo de Pesquisa de área a fim, e de um funcionário do setor de $\mathrm{EaD}$ da IES. Consideramos importante destacar que todos os sujeitos que participaram da avaliação do novo EDV3D, já possuíam alguma experiência com o metaverso SL.

Foram utilizados como instrumentos de pesquisa: questionários, observação da interação dos alunos com o novo EDV3D e um desafio em forma de notecard disposto no próprio metaverso SL. Foram avaliados aspectos pertinentes ao novo espaço, tais como: a Central de Teleporte, a locomoção dos avatares, a identidade da instituição e as possibilidades didático-pedagógicas do novo espaço.

A partir da observação direta realizada em um encontro presencial, em relação à utilização deste novo espaço foi possível constatar: a euforia e a motivação dos alunos em interagir com o novo EDV3D; que a utilização do novo EDV3D da IES possibilitou aos alunos a interação com as aplicações disponíveis no MDV3D através da telepresença, por meio de seus avatares, bem como os alunos demonstraram facilidade em utilizar e compreender a maior parte dessas aplicações; maior utilização do novo espaço, pois tendo em vista todos os recursos que o metaverso SL dispõe, foi possível desenvolver um espaço interativo, de fácil locomoção, acessível e motivador. Também se observou que os alunos sentiram-se motivados a produzir materiais, (por exemplo, notecards, dentro do novo EDV3D.

Em relação à análise dos questionários e a resolução dos desafios realizados na modalidade a distância, destacam-se os seguintes indicadores de análise:

\section{1- Central de Teleporte:}

Referente à central de teleporte que se encontra na entrada principal do novo EDV3D da IES, no que diz respeito à facilidade de utilização e se as informações contidas nesta central foram úteis e importantes no sentido de facilitar a exploração do novo EDV3D, todos os alunos responderam que tiveram facilidade no uso deste recurso, conforme o seguinte extrato de análise:

“- O teleporte é bem simples e bem orientado, o que facilita o entendimento do local para onde o objeto está teleportando" (sujeito 1 - colaborador de um Grupo de Pesquisa).

Ainda, relataram que as informações contidas na apresentação disposta na central foram de suma importância para o conhecimento dos espaços bem como seus respectivos objetivos:

“- Primeiramente visualizei todos os slides para conhecer o que encontraria em cada espaço. Deste modo, identificam-se também os objetivos dos referidos espaços" (sujeito 1 - colaborador de um Grupo de Pesquisa).

\section{2- Locomoção do avatares no novo EDV3D:}

Com o propósito de minimizar as dificuldades de locomoção encontradas no atual EDV3D da IES, utilizamos as próprias características da natureza do metaverso SL para oferecer várias formas de locomoção, proporcionando o deslocamento através de vôos, rampas de acesso e teleportes.

Através dos extratos de análise percebemos que este objetivo foi alcançado, conforme evidenciam os relatos: 
“- A parte de locomoção ficou muito boa. O espaço está bem agradável para a locomoção dos avatares. Facilitam aos que preferem ir andando do que ir voando, pois muitos sentem dificuldades de voar no SL" (sujeito 3 funcionário responsável pela equipe técnica do setor de EAD);

“- O fato de não haver portas e a entrada ser bem ampla facilita a locomoção dos avatares. As rampas trazem a idéia de acessibilidade" (aluna 4- Computação-Licenciatura);

“- Sim, as rampas facilitam a locomoção, estão bem visíveis alem de serem amplas, assim como o ambiente tem os móveis bem posicionados o que facilita a movimentação" (aluna2- Computação-Licenciatura).

\section{3- Identidade da Instituição:}

Tendo em vista a construção do novo EDV3D da IES de forma que expresse potencialmente a identidade da mesma e a finalidade didático-pedagógica do MDV3D no metaverso SL, destacamos os seguintes relatos:

“- A identidade institucional fica bem visível. Em todos os espaços pode-se perceber a identificação da IES através da utilização de sua logomarca” (sujeito 1 - colaborador de um Grupo de Pesquisa);

“-[...] está mais moderno, amplo, claro, de fácil movimentação, os móveis bem posicionados, o que facilita a locomoção, em resumo, bem melhor que o ambiente anterior. A arena também está organizada como também prática” (aluno 2 - Computação-Licenciatura).

Desse modo verificamos que o novo EDV3D também expressa potencialmente a identidade da instituição representada. Assim, corroboramos com Bruscato et al. (2008, p. 3) quando afirmam que os espaços a serem representados com a finalidade de identificar a instituição "precisam ser coerentes para que se faça uma leitura clara da sua organização, facilitando a compreensão e a legibilidade das partes ao usuário". Também destacamos que nesse contexto torna-se indispensável utilizar as características inovadoras em relação à natureza do meio, que é digital virtual.

\section{4- Possibilidades didático-pedagógicas do novo EDV3D:}

As possibilidades didático-pedagógicas encontradas no novo EDV3D são diversas, tais como telas de mídias com vídeos-aula, slide show, machinimas, painéis explicativos, espaços para apresentações de trabalhos, realização de processos formativos, eventos, enfim, cada profissional poderá utilizar esses espaços da forma mais adequada para sua disciplina e/ou curso em EaD, ou ainda, utilizando como apoio ao ensino presencial.

Nesse sentido, os alunos relatam que perceberam maior exploração das possibilidades didático-pedagógicas de uso desse novo espaço, conforme mostram os extratos de análise:

“- Os novos espaços ficaram muito bem estruturados e divididos. Além disso, foram planejados outros locais que são potencialmente ricos para o desenvolvimento de diversas atividades" (sujeito 1 - colaborador de um Grupo de Pesquisa);

“- O espaço Arena está bem interessante, houve cuidado com estética do ambiente, de forma que há harmonia de cores no ambiente. O espaço é interessante para realização de aulas e cursos" (aluno 4 - ComputaçãoLicenciatura);

“-Houve grande preocupação com os espaços para locomoção dos avatares, eles são amplos e fáceis de acessar. Acredito ter bem mais aplicabilidades didático-pedagógicas neste novo ambiente e de forma bem mais fácil e interativa de serem usados. Com relação à proposta pedagógica da instituição, ela está muito mais clara neste ambiente, houve uma enorme modernização da estrutura do espaço em questão" (aluna 5- ComputaçãoLicenciatura).

Assim, de acordo com a avaliação realizada, constatamos que o novo EDV3D contribui para expressar as finalidades didático-pedagógicas que o metaverso SL pode 
oferecer, na medida em que proporciona várias formas de comunicação e interação, bem como o suporte necessário para o desenvolvimento de atividades na modalidade a distância. Concordamos com Schlemmer e Backes quando apontam que:

Uma das potencialidades pedagógica do SL, está na variedade de formas de comunicação e interação que essa tecnologia propicia, seja pela linguagem textual, oral, gráfica e gestual, o que transforma as atuais possibilidades encontradas na Educação a Distância, revolucionando-a. (SCHLEMMER; BACKES, 2008b, p. 529)

\section{CONCLUSÃO}

A utilização adequada das TDVs na educação, por profissionais capacitados, possibilita a qualificação das atividades didático-pedagógicas, tanto para o professor quanto para o aluno. De acordo com as considerações aqui apresentadas, as TDVs e as tecnologias da Web 3D, através de metaversos-MDV3D apresentam diversas formas de interação e imersão, possibilitando assim uma aprendizagem mais significativa, pois os alunos deixam de ser passivos e tornam-se construtores do seu próprio aprendizado, adquirem e compartilham conhecimentos na medida em que interagem com essas tecnologias, tornando-se assim próativos no processo de construção do conhecimento.

Em relação à construção do novo EDV3D no metaverso-SL, constatamos que foi importante identificar quais são as concepções acerca do ensinar e do aprender que permeiam a construção dos espaços educacionais nesse metaverso, a fim de contemplar a identidade da instituição, bem como sua proposta pedagógica. Nesse sentido, também destacamos a importância da elaboração dos planejamentos Urbano e Arquitetônico e Técnico-DidáticoPedagógico, para evitar desperdício de tempo e de trabalho, uma vez que tais planejamentos devem nortear a construção de EDV3D e/ou MDV3D para melhor aproveitamento do espaço e das potencialidades pedagógicas oferecidas pelo metaverso-SL. Também esperamos através desse trabalho, ter mostrado a importância da utilização das TDVs e das tecnologias da Web $3 D$ no contexto educativo, bem como incentivar maior usabilidade do novo EDV3D pela instituição.

\footnotetext{
Notas do Texto

${ }^{1}$ A RICESU é uma Rede de Instituições Católicas de Ensino Superior sendo que o Centro Universitário La Salle/Unilasalle é uma das instituições que a compõem. A Ilha RICESU é a representação do espaço digital virtual da RICESU composta por espaços comuns à Rede tais como: espaços de trabalho colaborativo/cooperativo, espaços para reuniões, dentre outros, e por espaços destinados aos projetos específicos de cada uma das instituições que integram a RICESU.

${ }^{2}$ Entende-se por Web 2.0 a segunda geração da internet, que utiliza a web como plataforma e, dentre as principais características, destacam-se as possibilidades de interação, colaboração e cooperação;

2 Prims são blocos de construção em formatos geométricos (cubo, cilindro ou esfera) que unidos ou sozinhos formam um único objeto;

${ }^{4}$ Scketch significa esboço, por isso o Software ScketchUp é utilizado por arquitetos na fase inicial de seus projetos - para criação do esboço;

${ }^{5}$ Notecards são como blocos eletrônicos de anotações, onde pode ser inserido qualquer tipo de informação, até mesmo scripts para serem adicionados aos objetos.
} 


\section{REFERÊNCIAS}

BRUSCATO, M. U et al. Planejamento Urbano e Arquitetônico do Espaço Digital Vistual destinado a IESC - Planejamento da utilização do espaço da IESC na Ilha RICESU. GPE-du UNISINOS/CNPq/RICESU. Universidade do Vale do Sinos - UNISINOS, São Leopoldo.

LEMOS, CIBERCULTURA. Alguns pontos para compreender a nossa época. Porto Alegre, 2003.

Disponível

em: http://www.facom.ufba.br/ciberpesquisa/andrelemos/cibercultura.pdf - Acesso em: Março de de 2011.

LÉVY, P. Cibercultura. 2. ed. São Paulo: Editora 34, 2008.

MATTAR, J., VALENTE, C. Second Life e Web 2.0 na educação: o potencial revolucionário das novas tecnologias. São Paulo: Novatec, 2008.

SCHLEMMER, E., TREIN, D. Criação de Identidades Digitais Virtuais para Interação em Mundos Digitais Virtuais em 3D. 2008a. GPE-du UNISINOS/CNPq/RICESU. Universidade do Vale do Rio do Sinos - UNISINOS, São Leopoldo. Disponível em: http://www.abed.org.br/congresso2008/tc/515200815252PM.pdf - Acesso em: Março de 2011 SCHLEMMER, E., BACKES, L. Formação Docente e Possibilidades Didático Pedagógicas em Metaversos. 2008a. GPE-du UNISINOS/CNPq/RICESU, Universidade do Vale do Rio do Sinos - UNISINOS, São Leopoldo.

SCHLEMMER, E., BACKES, L. Metaverso: novos espaços para a construção do conhecimento. 2008b. Revista Diálogo Educacional: Programa de Pós Graduação em Educação da PUCPR, Curitiba, n.24, p.519-532.

SCHLEMMER, E et al. Planejamento técnico-didático-pedagógico do MDV3D. 2008. GPE-du UNISINOS/CNPq/RICESU, Universidade do Vale do Rio do Sinos - UNISINOS. São Leopoldo.

SCHLEMMER, E., TREIN, D., SOARES, H. C. M. Espaço de Convivência Digital Virtual (ECODI) RICESU: uma experiência em rede com a tecnologia de metaverso Second Life. GPE-du UNISINOS/CNPq/RICESU, Universidade do Vale do Rio do Sinos UNISINOS. São Leopoldo. Disponível em: http://gpedunisinos.wordpress.com/producao/artigos/ - Acesso em: Março de 2011. 